\title{
Diagnostischer Stellenwert und klinische Bedeutung der Analyse von T-Zellrezeptor-Genumlagerungen beim kutanen T-Zell-Lymphom
}

\section{Assaf}

\author{
The Impact of T-Cell Receptor Rearrangement Analysis in Cutaneous T-Cell \\ Lymphoma
}

\section{Zusammenfassung}

Kutane T-Zell-Lymphome (CTCL) stellen eine Gruppe lymphoproliferativer Hauterkrankungen dar, die durch klonale Akkumulation von T-Lymphozyten-Populationen charakterisiert sind. Die Diagnose wird in der Regel aufgrund klinischer und histologischer charakteristischer Eigenschaften der CTCL gestellt. Schwierigkeiten bereitet die Diagnosestellung insbesondere in frühen Stadien, aber auch in seltenen Varianten der CTCL. In diesen Fällen ist der Nachweis klonaler T-Zell-Populationen durch identisch umgelagerte T-Zellrezeptor-Gene eine wertvolle Hilfe. So zeigen PCR-basierende Techniken zum Nachweis klonaler T-Zell-Populationen eine hohe Sensitivität von $70-90$ \% in Hautbiopsien früher CTCL-Stadien. Nach Diagnosestellung ist der nächste wichtige Schritt die Ausbreitungsdiagnostik des CTCL, sinkt doch die Überlebensrate drastisch bei Auftreten extrakutaner Manifestationen wie z.B. bei Infiltration der Lymphknoten oder viszeraler Organe. Ein Stadienwechsel, d.h. die Progression der Erkrankung, wird in der Regel klinisch erst spät entdeckt. Insbesondere der Lymphknotenbefall, der erfahrungsgemäß als erste extrakutane Manifestation des CTCL gilt, stellt sowohl den Kliniker als auch den Histologen vor diagnostische Probleme. Hier konnten wir in einer aktuellen Studien zeigen, dass in ca. 50 \% der dermatopathischen Lymphknoten identische klonale T-ZellPopulationen wie in den CTCL-Läsionen der Haut nachweisbar sind. Des Weiteren zeigte sich, dass diese Patienten eine reduzierte Überlebensrate haben, ähnlich denen, die eine histologisch manifeste Lymphknoteninfiltration durch das CTCL haben. Diese Daten belegen, dass T-Zellrezeptor-Umlagerungsanalysen bei Patienten mit CTCL sowohl eine diagnostische als auch prognostische Bedeutung haben und somit ein akkurates Staging ermöglichen.

\section{Abstract}

Cutaneous T-cell lymphoma (CTCL) is a clonal lymphoproliferative malignancy primarily involving the skin. Routine diagnosis of CTCL is based on its characteristic clinical and histopathologic features. However, the broad clinical and histological spectrum of the disease, especially of its early stages and rare variants, often complicates the differentiation between malignant CTCL and benign lymphoproliferative or reactive skin diseases. In these cases demonstration of a clonal T-cell population by detection of identically rearranged T-cell receptor genes (TCR) provides an adjunct. Using this approach clonality could be demonstrated in $70-90 \%$ in CTCL biopsies of early stages by recent PCR-based studies, indicating a high sensitivity. After achieving the correct diagnosis the next important step is to stage the disease in CTCLpatients. Patients with CTCL usually have an indolent course with a 5 -year survival of approximately $87 \%$. However, in a significant number of patients the disease may progress and disseminated extracutaneous manifestations may develop involving the lymph nodes, blood and visceral organs. The prognosis for patients with widespread manifestation of CTCL beyond the skin is poor. Therefore, accurate evaluation in each individual case is crucial for an adequate, stage-adapted therapeutic approach. Determining the status of peripheral lymph nodes, generally the first site of extracutaneous dissemination is particularly important for clinical staging of patients with CTCL. Recently we could demonstrate in a large cohort of CTCL patients that nearly $50 \%$ of dermatopathic lymph nodes of CTCL patients harbor a clonal T-cell population. Moreover, clonal T-cell detection in dermatopathic lymph nodes of CTCL patients was associated with limited survival similar to patients with histologically confirmed lymph node involvement, whereas all patients without T-cell clonality in the lymph nodes were alive at the last follow-up. In

Institutsangaben

Klinik und Hochschulambulanz für Dermatologie, Charité - Campus Benjamin Franklin, Berlin

Korrespondenzadresse

Dr. med. Chalid Assaf · Klinik und Hochschulambulanz für Dermatologie, Charité - Campus Benjamin Franklin .

Fabeckstraße 60-62 · 14195 Berlin·E-mail: chalid.assaf@charite.de

Bibliografie

Akt Dermatol 2004; 30: 566-572 @ Georg Thieme Verlag KG Stuttgart · New York .

DOI 10.1055/s-2004-826133 · ISSN 0340-2541 
Die Mycosis fungoides ist ein niedrig malignes kutanes T-ZellLymphom mit bislang unklarer Ätiologie. Das klinische Bild ist im Anfangsstadium durch erythematöse Herde geprägt. Später kann es zu typischen Plaquebildungen kommen, und bei fortschreitender Erkrankung bilden sich Tumore der Haut. Das histologische Bild einer klassischen Mycosis fungoides im Plaque-Stadium ist charakterisiert durch ein bandförmiges T-Zell-Infiltrat im oberen Stratum papillare, bestehend aus kleinen und mittelgroßen Zellen, die typischerweise einen zerebriformen Zellkern aufweisen. Es besteht ein variabler Epidermotropismus, gelegentlich mit Ausbildung von intraepidermalen Mikroabszessen, den so genannten Pautrierschen Mikroabszessen.

Schwierigkeiten bereitet die Diagnosestellung insbesondere im Frühstadium der Erkrankung, da die Hautveränderungen im prämykosiden Stadium klinisch als auch histologisch leicht mit entzündlichen Dermatosen wie dem atopischen Ekzem oder der Psoriasis vulgaris sowie den Formen der Parapsoriasisgruppe verwechselt werden können. Zudem gibt es seltene lokalisierte oder generalisierte Formen mit pagetoider Ausbreitung (Pagetoide Retikulose vom Woringer Kolopp- und Ketron-Goodman-Typ) und verschiedene Sonderformen wie z.B. die hypopigmentierte Mycosis fungoides [1].

Die Immunhistologie als moderne Methode zur Objektivierung der histologischen Diagnose vermag Frühformen der Mycosis fungoides nicht sicher von reaktiven Läsionen zu unterscheiden, da die Zellen in der Regel kein auffälliges Markerprofil aufweisen, sondern klassische T-Zell-Oberflächenmarker exprimieren $(\mathrm{CD} 2, \mathrm{CD} 3, \mathrm{CD} 4, \mathrm{CD} 5, \mathrm{CD} 7)$, wie sie auch bei anderen entzündlichen Hauterkrankungen gefunden werden [2].

Obwohl die Mycosis fungoides nicht durch einen rasch-progressiven Verlauf gekennzeichnet ist, ist die Überlebensrate der Patienten doch entscheidend von 1) einer frühen Diagnosestellung und 2) einem akkuraten Staging der Erkrankung, die eine stadiengerechte Therapie des Patienten ermöglicht, abhängig. Mittlerweile sind molekularbiologische Methoden entwickelt worden, um bei histologisch suspekten T-Zell-reichen Hautinfiltraten monoklonale T-Zell-Populationen als Hinweis auf eine mögliche Malignität des Infiltrates nachzuweisen. Mit diesen Techniken konnten grundlegende Daten bezüglich der diagnostischen (sowohl in der primären Hautläsion als auch in der Ausbreitungsdiagnostik, z. B. Lymphknoten) als auch prognostischen Bedeutung von Klonalitätsuntersuchungen beim kutanen T-ZellLymphom gewonnen werden.

\section{Sicherung der Klonalität in der Diagnostik des kutanen T-Zell-Lymphoms}

Die Mycosis fungoides als häufigste Variante primär kutaner T-Zell-Lymphome (CTCL) ist initial nur auf die Haut beschränkt. Im weiteren Verlauf tritt jedoch bei einem Teil der Patienten eine Progression auf, zunächst mit Befall der hautnahen Lymphknoten, später auch der inneren Organe. Für Patienten in den frühen Stadien mit alleinigem Hautbefall (I-III) wurde eine 10-JahresÜberlebensrate zwischen 100 und 67,4\% errechnet [3-5]. Bei Auftreten extrakutaner Lymphommanifestationen sinkt die mittlere Überlebensrate drastisch auf nur 13 Monate [6,7]. Eine conclusion, these results suggest that TCR rearrangement analysis has an important impact in the initial diagnosis of CTCL and, moreover PCR analysis of lymph nodes is an important additional step in achieving an accurate clinical staging.

frühe Diagnosestellung ist daher besonders wichtig, wird doch die Prognose wesentlich durch den Zeitpunkt der Diagnosestellung bestimmt.

Die Diagnose der Mycosis fungoides ist allerdings sowohl klinisch als auch histologisch in den Frühstadien häufig schwierig zu stellen. Eine große Anzahl entzündlicher Dermatosen zeigt doch einer Mycosis fungoides ähnliche klinische und histologische Merkmale [8,9]. Insbesondere die histologischen Veränderungen beim Sézary-Syndrom sind häufig dezenter ausgeprägt als bei einer Mycosis fungoides im Plaque-Stadium, aber auch unspezifische Veränderungen werden häufig gesehen [10]. Histologische Veränderungen wie Pautriersche Mikroabszesse, epidermale Lymphozyten mit größerem Zellkern im Vergleich zu denen von dermalen Lymphozyten, finden sich meist nur bei Mycosis fungoides und sind daher recht zuverlässige Kriterien für die Diagnose. Sie finden sich allerdings nur bei einer kleineren Zahl von Mycosis fungoides-Fällen und sind daher nicht sensitiv [11]. Als weiterer erschwerender Faktor bei der histopathologischen Begutachtung früher Mycosis fungoides-Läsionen kommt die intra- und interindividuelle Variabilität der begutachtenden Dermatopathologen hinzu [12].

Diese Schwierigkeiten bei der differenzialdiagnostischen Abgrenzung von Frühstadien der Mycosis fungoides von chronischen Dermatosen führten zur Entwicklung molekularbiologischer Nachweismethoden. Diese beruhen auf der Tatsache, dass bei malignen T-Zell-Neoplasien eine klonale Proliferation von transformierten T-Zellen besteht. Die proliferierenden T-Zellen weisen daher eine identische hypervariable Region des T-ZellRezeptorgens (V-N-(D)-N'-J-Region) auf, die an die Tochterzellen weitergegeben werden [13]. Im Gegensatz dazu findet man bei reaktiven Geschehen unterschiedliche T-Zellen mit unterschiedlichen TCR-Genumlagerungen. Aufgrund dieses Charakteristikums eignet sich die hypervariable V-N-(D)-N'-J-Region in Kombination mit molekularbiologischen Analysemethoden als DNATumormarker klonaler T-Zellen (Abb. 1).

Anfangs stand die Southern-blot-Hybridisierungstechnik im Vordergrund, mit deren Hilfe sich klonale T-Zell-Populationen aus DNA-Extrakten aus schockgefrorenem Gewebe nachweisen ließen [14]. Die Southern-blot-Technik wurde jedoch in den letzten Jahren immer mehr von der PCR-Technik abgelöst, mit der man Untersuchungen auch an, in der Routine üblichen, Formalin-fixiertem und Paraffin-eingebettetem Material durchführen kann. Zudem ist die PCR-Technik sensitiver, mit geringerem Zeitund Kostenaufwand verbunden, und das Arbeiten mit radioaktivem Material ist nicht notwendig [15].

Aufgrund der einfacheren Konfiguration der TCR- $\gamma$-Gene werden überwiegend TCR- $\gamma$-PCR-Varianten verwendet. Zahlreiche TCR$\gamma$-PCR-Varianten, z. B. mit Verwendung von segmentspezifischen Primern, Konsensus-Primern, radioaktiv-markierten Primern, 


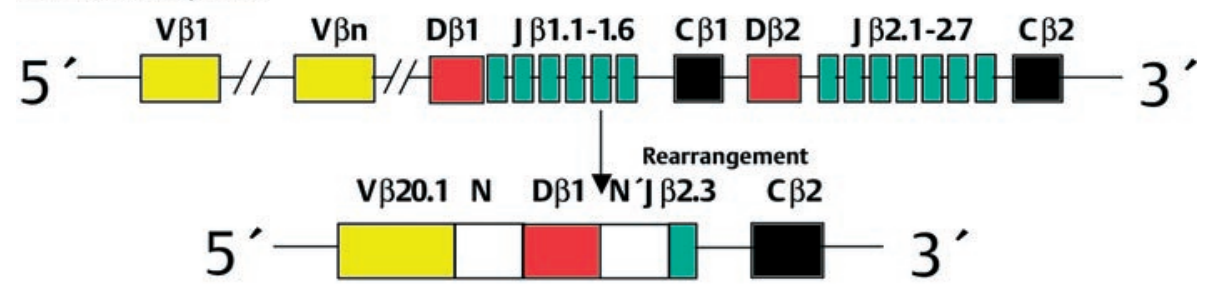

Abb. 1 Schematische Darstellung der Formation des TCR- $\beta$-Gens während des Umlagerungsprozesses.

GC-Klammer-Primer oder geschachtelte („nested“) PCR, kommen zum Einsatz. Mit diesen Methoden konnten bei der Mycosis fungoides unterschiedliche Detektionsraten von 53-90\% gefunden werden [16-18]. Hierbei war es bisher unklar, ob die voneinander weit divergierenden Nachweisraten durch die Anwendung verschiedener Techniken oder durch Untersuchung unterschiedlicher Stadien der Mycosis fungoides bedingt waren. Um diese Frage zu klären, untersuchten Dippel et al. klinisch und histologisch klar charakterisierte Mycosis fungoides-Fällen. Hierbei konnten sie mittels einer etablierten TCR- $\gamma$ PCR eine Nachweisrate von 76\% (16/21 Patienten) bei fortgeschrittenen Mycosis fungoides Fällen zeigen [19]. Diese Arbeit belegte erstmalig, dass auch in einem Teil der klinisch und histologisch klar definierten Lymphome der Nachweis einer T-Zell-Klonalität nicht gelingt.

Dass diese Einschränkung primär methodisch bedingt ist und diese Mycosis fungoides-Fälle doch in der überwiegenden Zahl der Fälle eine klonale T-Zell-Population enthalten, konnten wir in weiteren Experimenten zeigen [20]. Nach Entwicklung einer neuen TCR- $\beta$-PCR untersuchten wir insgesamt 24 Patienten mit Mycosis fungoides, einschließlich der 21 zuvor mit der TCR$\gamma$-PCR untersuchten Fälle. Hier konnten wir in allen Fällen (24/24) der fortgeschrittenen Mycosis eine T-Zell-Klonalität nachweisen. Diese Daten belegen eine signifikante Korrelation zwischen Klonalität und dem Vorliegen einer Mycosis fungoides. Der fehlende Nachweis klonaler TCR- $\gamma$-Genumlagerungen bei Vorhandensein klonaler TCR- $\beta$-Genumlagerungen ist wahrscheinlich durch die häufigen Mutationen im TCR- $\gamma$ - Genlokus bedingt [21]. Diese Mutationen des TCR- $\gamma$-Gens können möglicherweise nicht durch die verwendeten PCR-Primer erkannt werden und somit keine TCR- $\gamma$-spezifischen PCR-Produkte generiert werden. Dieses Phänomen ist auch bei den B-Zell-Lymphomen vom Keimzentrumstyp bekannt; sog. somatische Mutationen in den Immunglobulin-Genen sind die Ursache, dass in bis zu 30\% der Keimzentrums-Lymphome ein Klonalitätsnachweis nicht gelingt [22].

Die unterschiedlichen Nachweisraten sowohl bei Lymphomen als auch bei Kontrollen dürften häufig, wie bereits erwähnt, durch unterschiedliche PCR-Varianten, aber auch durch unterschiedliche Analysemethoden der PCR-Produkte bedingt sein.

Zur Identifizierung von PCR-Produkten stehen diverse Methoden zur Verfügung, die von der einfachen Agarose-Gel-Elektrophorese bis hin zur hochauflösenden Fraktionierung von Sequenzgelen reichen. Scheller et al. konnten zeigen, dass die Detektionsrate identischer klonaler PCR-Produkte mit Hilfe der PCR-Produktanalyse mit der Polacrylamid-Gelelektrophorese 42\% (22/53 CTCL-Fälle) und mit der Genescan-Analyse 62\% (33/53 CTCL-Fälle) beträgt [23]. Ferner zeigte sich, dass die Interpretation der
PCR-Produkte unter Verwendung der Denaturierenden-Gradienten- (DGGE) und der Temperaturgradienten-Gelelektrophorese (TGGE) mit möglicherweise starkem Hintergrundsignal häufig schwierig ist. Hier lässt die Bewertung von so genannten „schwachen Banden“ einen großen interpretatorischen Spielraum.

Eine wesentliche Verbesserung der Analysetechniken zum Nachweis von TCR- $\beta / \gamma$-Genumlagerungen wurde im Rahmen unserer Arbeiten durch den Einsatz von Primern erreicht, die mit Fluoreszenzfarbstoffen markiert waren und durch eine computergestützte Analyse in einem automatischen DNA-Sequenzierer ausgewertet wurden (Genescan-Analyse). Die elektrophoretische Auftrennung der PCR-Produkte fand analog zur Analyse von DNA-Sequenzierreaktionen in einem hochauflösenden denaturierenden Polyacryamid-Gel statt $[19,20,26]$. Das entwickelte Genescan-Verfahren ermöglicht durch präzise Größenbestimmung und Messung der Fluoreszenzintensität eine Trennschärfe von einem einzigen Basenpaar und gestattet damit eine objektive Unterscheidung monoklonaler von polyklonalen PCR-Produkten (Abb. 2).

Zusätzlich ist es möglich, durch die genaue Bestimmung der PCR-Produktgröße verschiedene Gewebeproben von gleichen Patienten, z. B. im Rahmen der Ausbreitungsdiagnostik oder Monitoring unter Therapie [24,25], zu vergleichen (Abb. 3). Die Kenntnis dieser technischen Unterschiede sowohl der Generierung als auch der Analyse der PCR-Produkte ist daher eine wichtige Voraussetzung bei der Bewertung einer Klonalität.

Nach Erkenntnis der Sensitivität verschiedener PCR-Methoden (TCR- $\gamma / \beta-P C R$ ) an klar definierten kutanen T-Zell-Lymphomen zeigen Untersuchungen an frühen Stadien der Mycosis fungoides eine Klonalität in ca. 70\% der Fälle [16-18,26]. Trotz der eingeschränkten Nachweisrate (keine Klonalität in ca. 30\%) scheint diese Methode sensitiver als jedes einzelne histologische Kriterium in den Frühstadien der Mycosis fungoides zu sein und damit eine zusätzliche diagnostische Hilfe [27].

Eine klare Abgrenzung eines Frühstadiums der Mycosis fungoides von einer Parapsoriasis en plaque ist mittels Klonalitätsuntersuchungen nicht möglich. So konnten Klemke et al. [26] in $19 \%$ (5/26) und Theodorou et al. [18] sogar in 100\% (5/5) eine klonale T-Zell-Population nachweisen. Hierbei muss kritisch bemerkt werden, dass eine sichere Differenzierung einer frühen Mycosis fungoides von einer großfleckigen Parapsoriasis klinisch und auch histologisch bisher nicht möglich ist. Nach Burg et al. entsprechen diese klonalen Parapsoriasisfälle möglicherweise doch einer Mycosis fungoides [28]. 


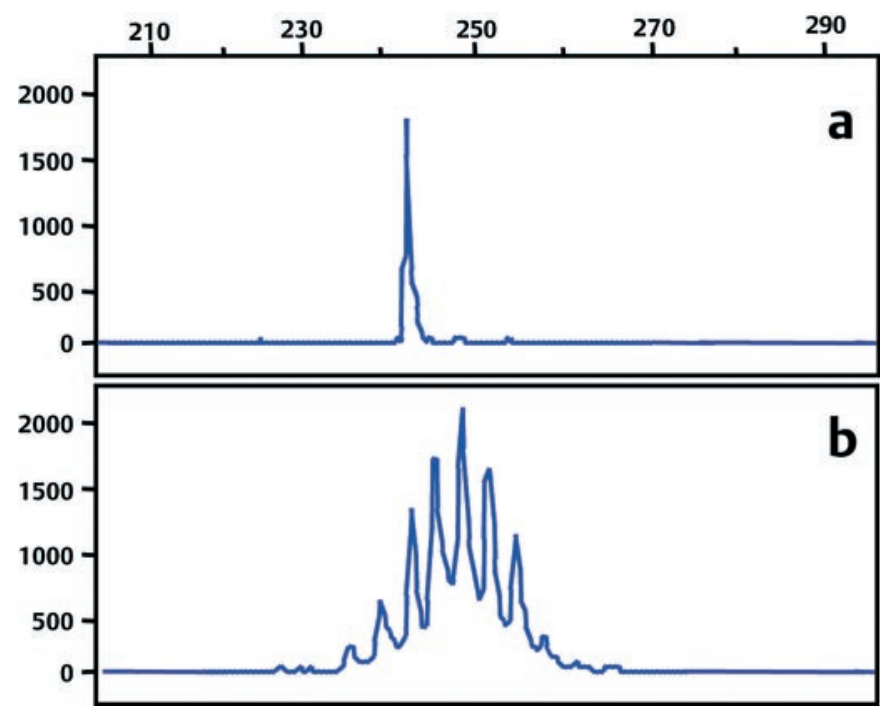

Abb. 2 GENESCAN-Analyse zum Nachweis von TCR- $\beta$-Genumlagerungen. a TCR- $\beta$-Umlagerung der T-Zell-Linie HutGut. Solitärer Peak (243 bp) als Beispiel einer monoklonalen T-Zell-Population. b TCR- $\beta$-Umlagerung von normalem Tonsillengewebe. Man erkennt ein der „Gaußschen Verteilungskurve“ ähnliches Bild mit einer Fragmentverteilung von 234 bp - 261 bp (polyklonale Proliferation). Die graphische Darstellung der Elektropherogramme erfolgt als quantitative Analyse der Fluoreszenzintensität (y-Achse) als Funktion der PCR-Fragmentlänge in bp (x-Achse).

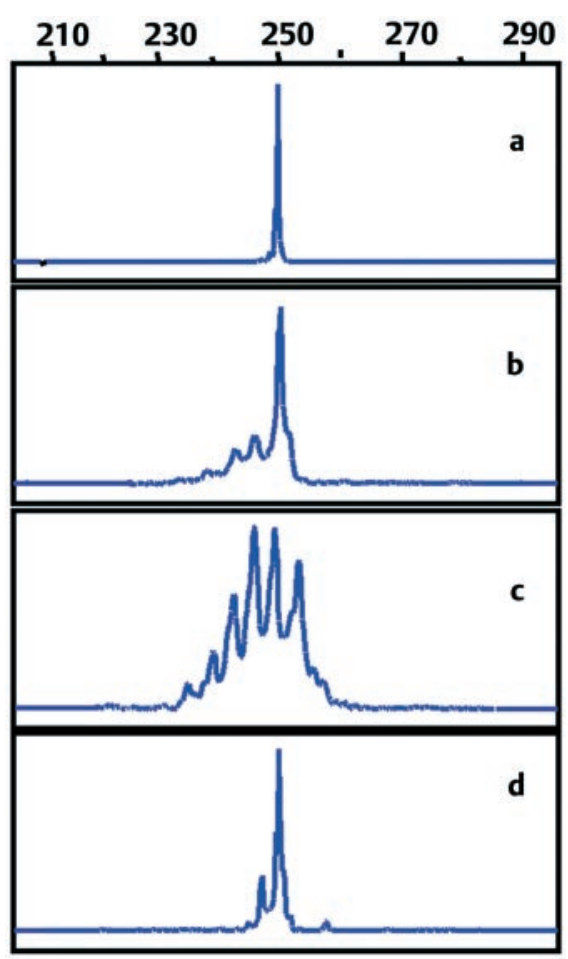

Abb. 3 Follow-up eines CTCL-Patienten mittels TCR$\beta$-PCR und GENESCAN-Analyse. a Plaque-Stadium zum Zeitpunkt der Erstdiagnose, b Lymphknotenbefall 6 Monate später, c peripheres Blut zum Zeitpunkt des Lymphknotenbefalls, d Hautrezidiv 2 Jahre später nach Chemotherapie. Zur Darstellung kommt die gleiche TCR- $\beta$-Umlagerung ( $250 \mathrm{bp})$ in allen Gewebeproben. Das periphere Blut ist nicht erkennbar befallen.

Eine weitere Herausforderung im klinischen Alltag ist die differenzialdiagnostische Abgrenzung von Erythrodermien bei kutanem T-Zell-Lymphom von entzündlichen Dermatosen. Hier konnten Cherny et al. [29] in einer retrospektiven Studie eine Klonalität in allen untersuchen Hautproben bei erythrodermischer Mycosis fungoides nachweisen, während Hautproben entzündlicher Dermatosen mit Erythrodermien, wie bei atopischer Dermatitis, generalisierter allergischer Kontaktdermatitis, Arz- neimittelreaktionen, Pityriasis rubra pilaris oder Psoriasis, polyklonal waren. Diese Ergebnisse konnten sowohl von Cordel et al. [30] als auch durch eigene Daten bestätigt werden und unterstreichen die Bedeutung dieser Analysen in der Differenzialdiagnostik bei Erythrodermien [19,20].

\section{Bedeutung der Klonalität in der Ausbreitungsdiagnostik}

Ist die Diagnose eines kutanen T-Zell-Lymphoms bei einem Patienten gestellt, so ist die nächste wichtige Frage das Stadium der Erkrankung, das für die Wahl sowie das Ansprechen der Therapie und damit letztendlich für das Überleben entscheidend ist [3-5]. Voraussetzung dafür ist eine akkurate sowie individuellangepasste Ausbreitungsdiagnostik. Ein Stadienwechsel wird in der Regel mit klinischen Mitteln erst spät entdeckt. Insbesondere der Nachweis des Befalls von Lymphknoten oder peripheren Blutes ist eine schwierige diagnostische Herausforderung. Mittels der TCR- $\gamma / \beta-P C R$ wurden hierzu in den letzten Jahren enorme Anstrengungen durchgeführt, klonale T-Zell-Populationen in den Rezirkulationsorganen zu detektieren.

Der Lymphknotenbefall, der erfahrungsgemäß als erste extrakutane Manifestation des kutanen T-Zell-Lymphoms gilt, stellt sowohl den Kliniker als auch den Histologen vor diagnostische Probleme. Vergrößerte Lymphknoten treten sowohl bei malignen Hauterkrankungen als auch bei ausgedehnten benignen entzündlichen Dermatosen auf. Sofern ein Antigen vorwiegend eine T-Zell-Reaktion hervorruft, bewirkt dies in den hautnahen Lymphknoten eine Verbreiterung des Parakortex und ggf. auch der interfollikulären Zonen [31]. Vermehrt sind nicht nur kleine T-Lymphozyten und T-Immunoblasten, sondern auch Antigenpräsentierende Zellen, wie die interdigitierenden Retikulumzellen, Makrophagen und Langerhans-Zellen, ebenso die sog. hochendothelialen Venolen. Histologisch entsprechen diese Veränderungen einer sog. „dermatopathischen Lymphadenopathie“, die eine Reaktion des Lymphknotens bei juckenden chronischen Hauterkrankungen verschiedenster Ursache (Ekzeme, Hautlymphome, atopischer Dermatitis u.a.) darstellt $[32,33]$. Typischerweise wird neben kutanen Antigenen auch Melanin in die Lymphknoten transportiert und in Makrophagen (Melanophagen) gespeichert. Bei der dermatopathischen Lymphadenopathie finden sich zusätzlich aktivierte T-Lymphozyten, die zytologisch ähnlich den atypischen malignen T-Zellen sein können (Abb. 4). Diese können weder morphologisch noch immunhistologisch in ihrer Dignität sicher charakterisiert werden, insbesondere bei Patienten mit kutanem T-Zell-Lymphom kann bei einer dermatopathischen Lymphadenopathie eine frühe Lymphknoteninfiltration weder sicher diagnostiziert noch ausgeschlossen werden [34].

Weiss et al. konnten erstmals basierend auf der Southern-blotHybridisierungstechnik zeigen, dass in dermatopathischen Lymphknoten von Patienten mit einem CTCL in der Mehrzahl der Fälle (7/9) eine monoklonale TCR- $\beta$-Umlagerung nachweisbar ist [35]. Diese Daten konnten durch nachfolgende Untersuchungen zum Teil unterstützt werden [36-38]. Erst kürzlich konnten wir anhand einer größeren Fallzahl mittels TCR- $\beta$ - und TCR- $\gamma$-PCR in Kombination mit der Genescan-Technik zeigen, dass sich eine klonale T-Zell-Population in 50\% der klinisch ver- 


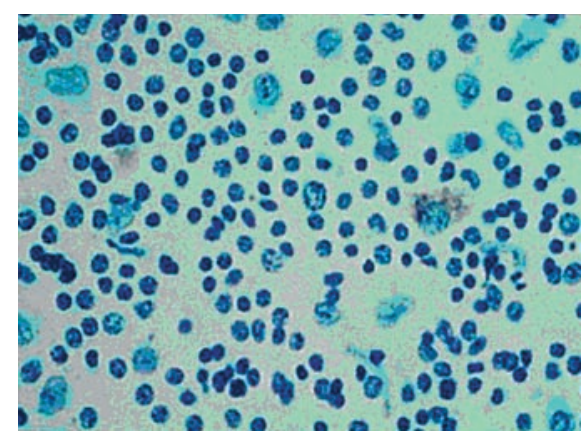

Abb. 4 Dermatopathische Lymphadenopathie. Expansion von z. T. atypisch anmutenden Lymphozyten. Nachweis von Melaninpigment in Makrophagen. Giemsafärbung, $\times 120$ größerten und histologisch als dermatopathisch klassifizierten Lymphknoten eine klonale T-Zell-Population nachweisen lässt. Darüber hinaus konnten wir erstmals anhand Größen- und Sequenzvergleich der PCR-Produkte zeigen, dass dieser T-Zell-Klon identisch mit dem malignen T-Zell-Klon in der korrespondierenden befallenen Hautläsion ist [39]. Dies beweist, dass die klonale T-Zell-Population im Lymphknoten eine Infiltration des Primärtumor, d. h. des kutanen Lymphoms repräsentiert (Abb. 5). Darüber hinaus zeigen diese Patienten mit nachweisbarem T-ZellKlon im Lymphknoten eine reduzierte Überlebensrate, auch wenn der Befall histologisch nicht manifest ist. Im Gegensatz dazu konnten in dermatopathischen Lymphknoten bei Patienten mit chronischen entzündlichen Dermatosen keine klonalen T-Zell-Populationen nachgewiesen werden [39]. Zusammenfassend belegen die bisherigen Southern-blot-Daten sowie insbesondere unsere Ergebnisse, dass die TCR- Klonalitätsanalysen eine wichtige Hilfe in der schwierigen Diagnostik bei suspektem Lymphknotenbefall durch ein kutanes T-Zell-Lymphom sind und dadurch ein akkurates Staging von Lymphompatienten ermöglichen.

Auch die Erkennung bzw. Charakterisierung atypischer maligner T-Zellen im peripheren Blut ist eine schwierige Aufgabe, die nicht nur der Ausbreitungsdiagnostik, sondern auch der Diagnosestel- lung eines Sézary-Syndroms dient. Mit dem Ziel eine Differenzierung zirkulierender Mycosis fungoides- bzw. Sézary-Zellen von atypischen reaktiven T-Zellen im Blut beim kutanen T-Zell-Lymphom zu ermöglichen, wurden bisher verschiedenste Eigenschaften untersucht. Jedoch lassen sich weder morphologische [40], immunphänotypische [41-43], ultrastrukturelle [44,45] Merkmale finden, die zuverlässig diese wichtige Unterscheidung ermöglichen. Hier erbrachte auch die Analyse der V $\beta$-Genexpression der T-Zell-Rezeptoren auf Proteinebene $[46,47]$ sowie der Nachweis chromosomaler Aberrationen $[48,49]$ bisher keine für die Routine praktischen Fortschritte.

Weiss et al. konnte 1989 als einer der ersten Forschergruppen beim Sézary-Syndrom mittels Southern-blotting klonale T-Zellen im Blut nachweisen [50]. Nur wenige Jahre später konnte mit dieser Technik die diagnostische Bedeutung des Klonalitätsnachweises im peripheren Blut bei der Differenzialdiagnose von Erythrodermien gezeigt werden [51] Ermutigt durch diese und nachfolgende Daten, beschloss daher die International Society of Cutaneous Lymphomas (ISCL) den Nachweis eines T-Zell-Klons im peripheren Blut als diagnostisches Kriterium für die Diagnose eines Sézary-Syndroms zu fordern $[52,53]$.

Die Untersuchung des Blutes im Rahmen der Ausbreitungsdiagnostik mittels Klonalitätsuntersuchungen gehört bisher nicht zur standardisierten Ausbreitungsdiagnostik. Mittels TCR$\beta / \gamma$-PCR-basierenden Arbeiten lassen sich T-Zell-Klone nicht nur in fortgeschrittenen Stadien, sondern auch in bis zu $57 \%$ der Fälle in frühen Stadien einer Mycosis fungoides detektieren. [54,55]. Einschränkend ist zu erwähnen, dass direkte Vergleiche der T-Zell-Klone von Haut und Blut in den vorangegangenen Studien häufig nicht durchgeführt wurden, so dass möglicherweise in einigen Fällen keine direkte Beziehung zwischen der klonalen T-Zell-Population der Haut und des peripheren Blutes besteht. Denn aktuelle Studien zeigen, dass sich klonale T-Zell-Populationen im peripheren Blut nicht nur bei Lymphompatienten, sondern auch bei älteren Gesunden und bei Patienten mit Autoim-
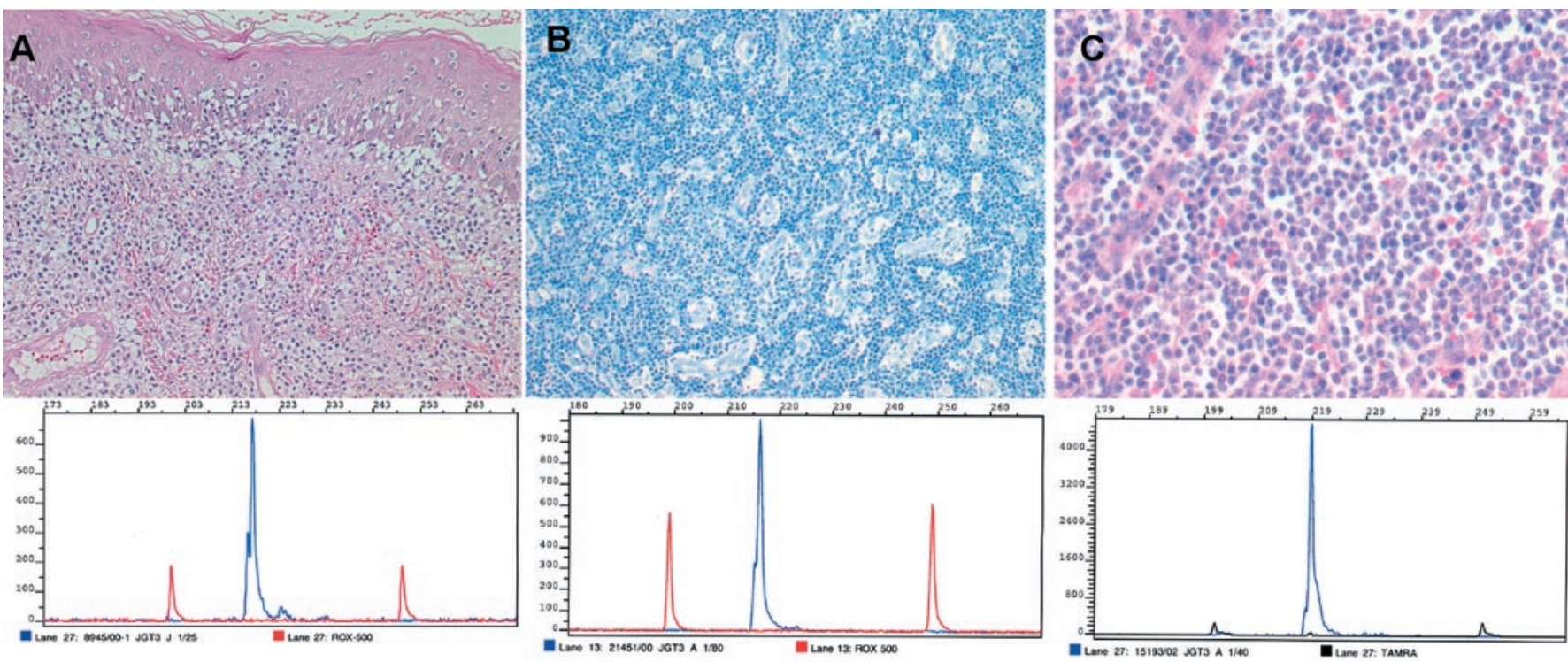

Abb 5 Nachweis einer klonalen T-Zell-Population in der Mycosis fungoides-Läsion in der Haut (A), im dermatopathischen Lymphknoten (B) und den zu einem späteren Zeitpunkt entnommenen, histologisch nachweisbar befallenen Lymphknoten (C). Die identische klonale T-Zell-Population, dargestellt mit der TCR- $\gamma$-PCR in Kombination mit der Genescan-Analyse (217 Basenpaare), ist in allen Proben nachweisbar. 
munerkrankungen nachweisen lassen [56-58]. Muche et al., die eine klonale T-Zell-Population in 13\% (5/38) bei Gesunden sowie in 38\% (3/8) bei Patienten mit Autoimmunerkrankungen im Blut gefunden haben, haben für dieses Phenomän den Ausdruck „T-cell expansion of undetermined significance (TEXUS)“ eingeführt, sozusagen als Pendant zur benignen monoklonalen Gammopathie undeterminierter Signifikanz [59]. Weitere Arbeiten konnten zeigen, dass gerade bei älteren Individuen klonale T-Zell-Klone im Blut nachweisbar sind, die von einer benignen klonalen Proliferation zytotoxischer T-Lymphozyten, sog. „T-cell large granular lymphocytes (T-LGL)“, abstammen [56,57]. Diese klonalen T-LGL proliferieren zum Teil als Antwort auf ein bestimmtes Antigen (z. B. Zytomegalievirus-Infektion). Möglicherweise proliferieren diese Zellen auch als Antwort auf ein kutanes T-Zell-Lymphom. Dies könnte erklären, warum verschiedene Arbeitsgruppen in bis zur Hälfte der Fälle im Blut T-Zell-Klone nachweisen konnten, die sich von den T-Zell-Klonen der läsionalen Haut bei Mycosis fungoides unterscheiden, d. h. nicht den Tumorzellklon repräsentieren [60,61]. Diese Daten zeigen, dass Klonalitätsanalysen im peripheren Blut im Rahmen der Ausbreitungsdiagnostik nur in Korrelation mit der klonalen T-Zell-Population der Haut möglich sind.

Zusammenfassend belegen diese Ergebnisse, dass Klonalitätsuntersuchungen bei kutanen T-Zell-Lymphomen sowohl in der Primär- als auch in der Ausbreitungsdiagnostik, insbesondere mit Kenntnis der methodischen und physiologischen Grundlagen, einen hohen Stellenwert haben. Für den maximalen Informationsgewinn sollten Klonalitätsergebnisse jedoch immer in Zusammenschau mit den klinischen und histologischen Gegebenheiten beurteilt werden.

Perspektivisch gilt es zunächst die Techniken der Klonalitätsanalysen in den Laboren zu standardisieren, um für die Diagnostik und die Ausbreitungsuntersuchungen vergleichbare Ausgangsbedingungen und schließlich Daten zu haben. Hierzu hat sich bereits eine europäische Projektgruppe ausgebildet, BIOMED-2 concerted action [62], die sich mit der Entwicklung neuer Primer für T-Zellrezeptor- und Immunglobulingene befasst.

\section{Literatur}

${ }^{1}$ Diamandidou E, Cohen PR, Kurzrock R. Mycosis fungoides and Sézary syndrome. Blood 1996; 88: 2385-409

2 Balfour EM, Glusac EJ, Heald P, Talley LL, Smoller BR. Sezary syndrome: cutaneous immunoperoxidase double-labeling technique demonstrates CD4/CD8 ratio non-specificity. J Cutan Pathol 2003; 30: 437 442

${ }^{3}$ Hoppe RT, Wood GS, Abel EA. Mycosis fungoides and the Sézary syndrome: pathology, staging, and treatment. Curr Probl Cancer 1990; 14: $293-371$

${ }^{4}$ Diamandidou E, Cohen PR, Kurzrock R. Mycosis fungoides and Sézary syndrome. Blood 1996; 88: 2385-409

${ }^{5}$ Zackheim HS, Amin S, Kashani-Sabet M, McMillan A. Prognosis in cutaneous T-cell lymphoma by skin stage: long-term survival in 489 patients. J Am Acad Dermatol 1999; 40: 418-25

${ }^{6}$ Diamandidou E, Colome M, Fayad L, Duvic M, Kurzrock R. Prognostic factor analysis in mycosis fungoides/Sézary syndrome. J Am Acad Dermatol 1999; 40: 914-924

${ }^{7}$ De Coninck EC, Kim YH, Varghese A, Hoppe TR. Clinical characteristics and outcome of patients with extracutaneous mycosis fungoides. J Clin Oncol 2001; 19: 779- 784
${ }^{8}$ Kohler S, Kim YH, Smoller BR. Histologic criteria for the diagnosis of erythrodermic mycosis fungoides and Sezary syndrome: a critical reappraisal. J Cutan Pathol 1997; 24: 292 - 297

${ }^{9}$ Smoller BR. Pathol Case Rev 1996; 1: $158-162$

${ }^{10}$ Trotter MJ, Whittaker SJ, Orchard GE, Smith NP. Cutaneous histopathology of Sézary syndrome: a study of 41 cases with a proven circulating T-cell clone. J Cutan Pathol 1997; 24: 286-291

${ }^{11}$ Glusac EJ. Criterion by criterion, mycosis fungoides. Am J Dermatopathol 2003; 25: 264-269

12 Olerud JE, Kulin PA, Chew DE, Carlsen RA, Hammar SP, Weir TW, Patterson SD, Bolen JW, Kadin ME, Barker E et al. Cutaneous T-cell lymphoma. Evaluation of pretreatment skin biopsy specimens by a panel of pathologists. Arch Dermatol 1992; 128: 501-507

${ }^{13}$ Alt FW, Oltz EM, Young F, Gorman J, Taccioli G, Chen J. VDJ recombination. Immunol Today 1992; 13: 306-314

${ }^{14}$ Bourguin A, Tung R, Galili N, Sklar J. Rapid, nonradioactive detection of clonal T-cell receptor gene rearrangements in lymphoid neoplasms. Proc Natl Acad Sci USA 1990; 87: 8536-8540

${ }^{15}$ Hodges E, Krishna MT, Pickard C, Smith JL. Diagnostic role of tests for T-cell receptor (TCR) genes. J Clin Pathol 2003; 56: 1 - 11

${ }^{16}$ Bottaro M, Berti E, Biondi A, Migone N, Crosti L. Heteroduplex analysis of T-cell receptor gamma gene rearrangements for diagnosis and monitoring of cutaneous T-cell lymphomas. Blood 1994; 83: 3271 - 3278

17 Wood GS, Tung RM, Haeffner AC, Crooks CF, Liao S, Orozco R, Veelken H, Kadin ME, Koh H, Heald P, Barnhill RL, Sklar J. Detection of clonal $\mathrm{T}$-cell receptor gamma gene rearrangements in early Mycosis fungoides/sézary syndrome by polymerase chain reaction and denaturing gradient gel electrophoresis (PCR/DGGE). J Invest Dermatol 1994; 103: $34-41$

18 Theodorou I, Delfau LarueMH, Bigorgne C, Lahet C, Cochet G, Bagot M, Wechsler J, Farcet JP. Cutaneous T-cell infiltrates: Analysis of T-cell receptor gamma gene rearrangement by polymerase chain reaction and denaturing gradient gel electrophoresis. Blood 1995; 86: 305-310

${ }^{19}$ Dippel E, Assaf C, Hummel M, Schrag HJ, Stein H, Goerdt S, Orfanos CE. Clonal T-cell receptor gamma-chain gene rearrangement by PCR-based GeneScan analysis in advanced cutaneous T-cell lymphoma: a critical evaluation. J Pathol 1999; 188: 46 - 154

${ }^{20}$ Assaf C, Hummel M, Dippel E, Goerdt S, Muller HH, Anagnostopoulos I, Orfanos CE, Stein $\mathrm{H}$. High detection rate of T-cell receptor beta chain rearrangements in T-cell lymphoproliferations by family specific polymerase chain reaction in combination with the GeneScan technique and DNA sequencing. Blood 2000; 96: 640-646

${ }^{21}$ Yoshikai Y, Toyonaga B, Yasuhiro K, Kimura N, Griesser H, Mak TW. Repertoire of the human T-cell gamma genes: High frequency of nonfunctional transcripts in thymus and mature T cells. Eur J Immunol 1987; 17: $119-126$

${ }^{22}$ Harris NL, Stein H, Coupland SE, Hummel M, Favera RD, Pasqualucci L, Chan WC. New approaches to lymphoma diagnosis. Hematology (Am Soc Hematol Educ Program) 2001; $194-220$

${ }^{23}$ Scheller U, Muche JM, Sterry W, Lukowsky A. Detection of clonal T cells in cutaneous $\mathrm{T}$ cell lymphoma by polymerase chain reaction: comparison of mutation detection enhancement-polyacrylamide gel electrophoresis, temperature gradient gel electrophoresis and fragment analysis of sequencing gels. Electrophoresis 1998; 19: 653-658

24 Assaf C, Hummel M, Dippel E et al. Common clonal T-cell origin in patient with T-prolymphocytic leukemia and associated cutaneous T-cell lymphomas. Br J Hematol 2003; 120: 488 - 491

${ }^{25}$ Assaf C, Hummel M, Zemlin M, Steinhoff M, Geilen CC, Stein H, Orfanos CE. Transition of Sezary syndrome into mycosis fungoides after complete clinal and molecular remission under extracorporeal photophoresis. J Clin Pathol 2004; 57: 1325 - 1328

${ }^{26}$ Klemke CD, Dippel E, Dembinski A, Ponitz N, Assaf C, Hummel M, Stein $\mathrm{H}$, Goerdt $\mathrm{S}$. Clonal $\mathrm{T}$ cell receptor gamma-chain gene rearrangement by PCR-based GeneScan analysis in the skin and blood of patients with parapsoriasis and early-stage mycosis fungoides. J Pathol 2002; 197: $348-354$

${ }^{27}$ Bergman R. How useful are T-cell receptor gene rearrangement studies as an adjunct to the histopathologic diagnosis of mycosis fungoides? Am J Dermatopathol 1999; 21: 498 - 502

${ }^{28}$ Burg G, Dummer R, Haeffner A, Kempf W, Kadin M. From inflammation to neoplasia: mycosis fungoides evolves from reactive inflammatory conditions (lymphoid infiltrates) transforming into neoplastic plaques and tumors. Arch Dermatol 2001; 137: 949-952

${ }^{29}$ Cherny S, Mraz S, Su L, Harvell J, Kohler S. Heteroduplex analysis of T-cell receptor gamma gene rearrangement as an adjuvant diagnostic 
tool in skin biopsies for erythroderma. J Cutan Pathol 2001; 28: 351 355

${ }^{30}$ Cordel N, Lenormand B, Courville P, Lauret P, Joly P. Detection of clonal T-cell receptor gamma gene rearrangement with the use of PCR-DGGE for diagnosis of erythroderma. Ann Dermatol Venereol 2001; 128: $220-223$

${ }^{31}$ Geissmann F, Dieu-Nosjean MC, Dezutter C, Valladeau J, Kayal S, Leborgne M, Brousse N, Saeland S, Davoust J. Accumulation of immature Langerhans cells in human lymph nodes draining chronically inflamed skin. J Exp Med 2002; 196: 417 - 430

32 Rausch E, Kaiserling E, Goos M. Langerhans cells and interdigitating reticulum cells in the thymus-dependent region in human dermatopathic lymphadenitis. Virchows Arch B Cell Pathol 1977; 25: 327 - 343

33 van der Valk P, Meijer CJ. The histology of reactive lymph nodes. Am J Surg Pathol 1987; 11: 866-882

${ }^{34}$ Weiss LM, Wood GS, Warnke RA. Immunophenotypic differences between dermatopathic lymphadenopathy and lymph node involvement in mycosis fungoides. Am J Pathol 1985; 120: 179-185

${ }^{35}$ Weiss LM, Hu E, Wood GS, Moulds C, Cleary ML, Warnke R, Sklar J. Clonal rearrangements of T-cell receptor genes in mycosis fungoides and dermatopathic lymphadenopathy. N Engl J Med 1985; 313: 539 544

${ }^{36}$ Lynch JW Jr., Linoilla I, Sausville EA, Steinberg SM, Ghosh BC, Nguyen DT, Schechter GP, Fischmann AB, Ihde DC, Stocker JL, Bastian A, Turner R, Cotelingam JD, Gazdar AF, Foss FM. Prognostic implications of evaluation for lymph node involvement by T-cell antigen receptor gene rearrangement in mycosis fungoides. Blood 1992; 79: 3293-3299

37 Bakels V, Van Oostveen JW, Geerts ML, Gordijn RL, Walboomers JM, Scheffer E, Meijer CJ, Willemze R. Diagnostic and prognostic significance of clonal T-cell receptor beta gene rearrangements in lymph nodes of patients with mycosis fungoides. J Pathol 1993; 170: 249255

${ }^{38}$ Kern DE, Kidd PG, Moe R, Hanke D, Olerud JE. Analysis of T-cell receptor gene rearrangement in lymph nodes of patients with mycosis fungoides. Prognostic implications. Arch Dermatol 1998; 134: 158 - 164

39 Assaf C, Hummel M, Steinhoff M, Geilen CC, Orawa H, Stein H, Orfanos CE. Early TCR- $\beta$ and TCR- $\gamma$ PCR detection of clonality indictes minimal tumor disease in lymph nodes of cutaneous T-cell lymphoma: diagnostic and prognostic implications. Blood 2004: Online-Publication 30.9.2004

${ }^{40}$ Vonderheid EC, Sobel EL, Nowell PC, Finan JB, Helfrich MK, Whipple DS. Diagnostic and prognostic significance of Sezary cells in peripheral blood smears from patients with cutaneous T cell lymphoma. Blood 1985; 66: 358-366

${ }^{41}$ Sterry W, Mielke V. CD4+ cutaneous T-cell lymphomas show the phenotype of helper/inducer T cells (CD45RA-, CDw29+). J Invest Dermatol 1989; 93: $413-416$

42 Wood GS, Hong SR, Sasaki DT, Abel EA, Hoppe RT, Warnke RA, Morhenn VB. Leu-8/CD7 antigen expression by CD3+ T cells: comparative analysis of skin and blood in mycosis fungoides/Sezary syndrome relative to normal blood values. J Am Acad Dermatol 1990; 22: 602 - 607

${ }^{43}$ Bernengo MG, Quaglino P, Novelli M, Cappello N, Doveil GC, Lisa F, de Matteis A, Fierro MT, Appino A. Prognostic factors in Sezary syndrome: a multivariate analysis of clinical, haematological and immunological features. Ann Oncol 1998; 9: 857-863

${ }^{44}$ Payne CM, Glasser L. Ultrastructural morphometry in the diagnosis of Sezary syndrome. Arch Pathol Lab Med 1990; 114: 661 -671

${ }^{45}$ Preesman AH, Schrooyen SJ, Toonstra J, van der Putte SC, Rademakers LH, Willemze R, van Vloten WA. The diagnostic value of morphometry on blood lymphocytes in erythrodermic actinic reticuloid. Arch Dermatol 1995; 131: 1298 - 1303

${ }^{46}$ Gorochov G, Bachelez H, Cayuela JM, Legac E, Laroche L, Dubertret L, Sigaux F. Expression of V beta gene segments by Sezary cells. J Invest Dermatol 1995; 105: 56-61
${ }^{47}$ Bigler RD, Boselli CM, Foley B, Vonderheid EC. Failure of anti-T-cell receptor $\mathrm{V}$ beta antibodies to consistently identify a malignant T-cell clone in Sezary syndrome. Am J Pathol 1996; 149: 1477-1483

${ }^{48}$ Limon J, Nedoszytko B, Brozek I, Hellmann A, Zajaczek S, Lubinski J, Mrozek K. Chromosome aberrations, spontaneous SCE, and growth kinetics in PHA-stimulated lymphocytes of five cases with Sezary syndrome. Cancer Genet Cytogenet 1995; 83: 75-81

${ }^{49}$ Thangavelu M, Finn WG, Yelavarthi KK, Roenigk HH, Jr., Samuelson E, Peterson L, Kuzel TM, Rosen ST. Recurring structural chromosome abnormalities in peripheral blood lymphocytes of patients with mycosis fungoides/Sézary syndrome. Blood 1997; 89: 3371 - 3377

50 Weiss LM, Wood GS, Hu E, Abel EA, Hoppe RT, Sklar J. Detection of clonal T-cell receptor gene rearrangements in the peripheral blood of patients with mycosis fungoides/Sezary syndrome. J Invest Dermatol 1989; 92: $601-604$

${ }^{51}$ Bakels V, van Oostveen JW, Gordijn RL, Walboomers JM, Meijer CJ, Willemze R. Diagnostic value of T-cell receptor beta gene rearrangement analysis on peripheral blood lymphocytes of patients with erythroderma. J Invest Dermatol 1991; 97: 782-786

52 Vonderheid EC, Sobel EL, Nowell PC, Finan JB, Helfrich MK, Whipple DS. Diagnostic and prognostic significance of Sezary cells in peripheral blood smears from patients with cutaneous T cell lymphoma. Blood 1985; 66: $358-366$

${ }^{53}$ Vonderheid EC, Bernengo MG, Burg G, Duvic M, Heald P, Laroche L, Olsen E, Pittelkow M, Russell-Jones R, Takigawa M, Willemze R. ISCL Update on erythrodermic cutaneous T-cell lymphoma: report of the International Society for Cutaneous Lymphomas. J Am Acad Dermatol 2002; 46: 95 - 106

${ }^{54}$ Fraser-Andrews EA, Woolford AJ, Russell-Jones R, Seed PT, Whittaker $\mathrm{SJ}$. Detection of a peripheral blood T cell clone is an independent prognostic marker in mycosis fungoides. J Invest Dermatol 2000; 114: 117 121

${ }^{55}$ Muche JM, Lukowsky A, Asadullah K, Gellrich S, Sterry W. Demonstration of frequent occurrence of clonal T cells in the peripheral blood of patients with primary cutaneous T-cell lymphoma. Blood 1997; 90: $1636-1642$

56 Posnett DN, Sinha R, Kabak S, Russo C. Clonal populations of T cells in normal elderly humans: the $\mathrm{T}$ cell equivalent to "benign monoclonal gammapathy". J Exp Med 199; 179: 609-618

57 Schwab R, Szabo P, Manavalan JS, Weksler ME, Posnett DN, Pannetier C, Kourilsky P, Even J. Expanded CD4+ and CD8+ T cell clones in elderly humans. Immunol 1997; 158: $4493-4499$

${ }^{58}$ Khan N, Shariff N, Cobbold M, Bruton R, Ainsworth JA, Sinclair AJ, Nayak L, Moss PA. Cytomegalovirus seropositivity drives the CD8 T cell repertoire toward greater clonality in healthy elderly individuals. J Immunol 2002; 169: 1984-1992

${ }^{59}$ Muche JM, Sterry W, Gellrich S, Rzany B, Audring H, Lukowsky A. Peripheral blood T-cell clonality in mycosis fungoides and nonlymphoma controls. Diagn Mol Pathol 2003; 12: $142-150$

60 Delfau-Larue MH, Laroche L, Wechsler J, Lepage E, Lahet C, Asso M, Bagot M, Farcet JP. Diagnostic value of dominant T-cell clones in peripheral blood in 363 patients presenting consecutively with a clinical suspicion of cutaneous lymphoma. Blood 2000; 96: 2987-2992

${ }^{61}$ Beylot-Barry M, Sibaud V, Thiebaut R, Vergier B, Beylot C, Delaunay M, Chene G, Dubus P, Merlio JP. Evidence that an identical T cell clone in skin and peripheral blood lymphocytes is an independent prognostic factor in primary cutaneous $T$ cell lymphomas. J Invest Dermatol 2001; 117: 920-926

62 van Dongen JJ, Langerak AW, Bruggemann M, Evans PA, Hummel M, Lavender FL, Delabesse E, Davi F, Schuuring E, Garcia-Sanz R, van Krieken JH, Droese J, Gonzalez D, Bastard C, White HE, Spaargaren M, Gonzalez M, Parreira A, Smith JL, Morgan GJ, Kneba M, Macintyre EA. Design and standardization of PCR primers and protocols for detection of clonal immunoglobulin and T-cell receptor gene recombinations in suspect lymphoproliferations: report of the BIOMED-2 Concerted Action BMH4-CT98 - 3936. Leukemia 2003; 17: 2257-317 